\title{
Correction: Validation of a clinical prediction rule for ambulation outcome after non-traumatic spinal cord injury
}

\author{
Rodney Sturt • Bridget Hill • Anne Holland - Peter W. New $($ Chloe Bevans
}

Published online: 14 April 2020

(c) International Spinal Cord Society 2020

Correction to: Spinal Cord

https://doi.org/10.1038/s41393-019-0386-x

published online 25 November 2019

In the original version of this article the order of the author list was incorrectly displayed as follows:

Rodney Sturt ${ }^{1}$, Chloe Bevans ${ }^{1}$, Bridget Hill ${ }^{1,2}$, Anne Holland ${ }^{1,3}$, Peter W. New ${ }^{2,4,5}$
This has now been corrected to:

Rodney Sturt ${ }^{1}$, Bridget Hill ${ }^{1,2}$, Anne Holland ${ }^{1,3}$, Peter W. $\mathrm{New}^{2,4,5}$, Chloe Bevans ${ }^{1}$

This has been corrected in both the PDF and HTML versions of the article. 